\title{
The Journey to a Wider Understanding of Ways of Knowing: Knowledge Translation and the Arts
}

\author{
Katherine Boydell
}

\begin{abstract}
In this commentary, educator and author Katherine Boydell reflects on her journey to incorporate art genres in the research process as a knowledge translation strategy for producing and disseminating research-informed knowledge. She highlights the need to move beyond descriptions of form and content to grapple with the unique methodological, theoretical, and ethical challenges of working with research participants, artists, and audience members engaging in this work. She describes some of her current artsbased research and identifies the current pressures to conform to expectations regarding "what counts" in academia and concludes with future suggestions to advance arts-based knowledge translation.
\end{abstract}

Can you talk a little bit about your academic background?

I began my research career as a community health epidemiologist, focused on identifying predictors of psychiatric rehospitalization using life table and other quantitative analyses. Very early into this work, I was confronted with a critical dilemma-what research participants were saying about their lives in the community and what the psychometrically sound and tested measurement instruments were telling us were profoundly different. Although symptomatology, level of functioning, and housing satisfaction scales were showing positive outcomes, personal narratives revealed a radically different story-one of isolation and loneliness, lack of meaningful activity, and deplorable housing conditions. This led me to return to graduate studies and pursue a degree in qualitative sociology, with the aim of focusing on understanding the in-depth and richly textured nature of the phenomena under research investigation, whether it be a lived experience, experience of an intervention, service or support, or a social contextwith a view to social change.

Where did this training in qualitative inquiry then take you?

I remained focused on research in the mental health field, equipped with the knowledge and skills to effectively interview in depth, facilitate focus groups, engage in participant and non-participant observation, and conduct critical analyses of data with strong theoretical and conceptual underpinnings. However, it was not long until I faced another challenge. The research results that we were generating were reaching our scholarly audience via peer-reviewed publications and scientific presentations, but my team and I worried about the failure of these methods to reach the service providers, policy makers, consumers of health services and their families, and the general public at large. Research articles are often not accessible, not understandable, and not adaptable to these important research stakeholders (Parsons \& Boydell, 2012; Hodgins \& Boydell, 2014). One research participant (a family member of an 
adult child with schizophrenia) asked us what happens to the research and stated that if they knew it helped even one other person, then their time and involvement as a research participant would have been worthwhile. As a result, my research team began to share our results in ways that we believed would be more appropriately shared beyond academia. We trained research participants to use cameras to take photographs of their neighborhood in a study on supported housing. We involved a research participant in a performative rendering of research on community-based participatory inquiry. We partnered with the film department at a local rural university to create a documentary highlighting the narratives of family caregivers seeking mental health services and supports for their children (Tilleczek \& Loebach, 2015). This documentary was used in "town hall" type public dissemination events in rural communities. The film was also incorporated in the teaching of allied health care professionals in college settings across the country. Audience responses to communicating our research results in this manner were very positive and motivated us to move toward a more serious consideration of formally using such creative methods in the research process.

So, why use creative methods in the research process?

There is much evidence to demonstrate that the arts have a significant role in portraying issues essential to our understandings of health, illness, and the body (Cox \& Boydell, 2016). Such arts-based methodologies and initiatives represent a new paradigm for social inquiry and innovation in qualitative research. Many health researchers are using the arts creatively to generate new knowledge and communicate research findings. A range of artistic genres are employed: performative, visual, and literary, which include photography and other visual arts, theatre, music, poetry and dance, digital storytelling, body mapping, and material objects. The benefits of using the arts in research include increased attention to the meaning and experience of health and illness, inclusion of disenfranchised and marginalized communities, and the heightened ability to convey research findings in a way that engages target audiences and facilitates change in health care knowledge, attitudes, and practice (Boydell, Solimine, \& Jackson, 2015; Boydell et al., 2018a; Boydell, Gladstone, Stasiulis, Nodin, \& Cheng, 2018b; Gray \& Kontos, 2015; Cole \& Knowles, 2008). On a global level, there has been a continual increase in the number and variety of health research projects adopting an arts-based approach to creating research knowledge and/or disseminating empirical research findings.

Can you describe some of your work in arts-based knowledge translation?

My research program is collaborative and participatory. Our creative and research team has used dance (Boydell 2011a, 2011b), mural art (Boydell et al., 2015b), digital storytelling (de Jager, Tewson, Vaughan, Fogarty, \& Boydell, 2017; Boydell \& Belliveau, 2017), body mapping (de Jager, Tewson, Ludlow, \& Boydell, 2016; Boydell et al., 2018a), material objects (Romano, McCay, \& Boydell, 2012), and multimedia installation art to disseminate research on pathways to mental health care, the experience of mental ill health, and perspectives on novel interventions.

One recent example of our work in this area has been the use of body mapping to explore the experiences of young people with psychosis (Boydell et al., 2018a). Body mapping is a way of telling stories; 
body maps are created using drawing, painting, or other arts-based approaches that visually represent aspects of individuals' lives, their bodies, and the world in which they live. It involves tracing the body of the participant onto a large piece of cloth or paper, which is subsequently embellished with visual representations of the participants' life narrative (Solomon, 2002).

In our research, via a series of facilitated workshops, young people were encouraged to reflect on their experiences of a 12-week physical health intervention, consider what narrative to tell, and how to represent it visually. They were asked to create an outline of their body and subsequently to use symbols and slogans to express their experiences of the physical health intervention and its impact on their lives. Following the body mapping process, participants were interviewed in depth about their experience and this interview was used to co-create a brief testimonio, or key to the body map (Figure 1). Thematic analysis and narrative inquiry were used to analyze the body maps. The narrative trope was one of recovery, highlighting the importance of the link between body and mind, individual and community, and the balance between light and darkness. Despite the pervasiveness of experiences of stigma and discrimination, there was an emphasis on developing feelings of connectedness (to self and others), hope and optimism for the future, and a sense of meaning and empowerment. Involvement in the body mapping process was consistently identified as therapeutic, offering an opportunity for reflection on the journey to recovery with a focus on past, present, and imagined storylines of the future. In this work, we highlight that the notion of embodied consciousness is contrary to a dualistic understanding of the mind and body. This shift in thinking is concisely expressed by Merleau-Ponty's point that, "we do not have bodies, we are our bodies" (de Jager et al., 2016, p. 13).

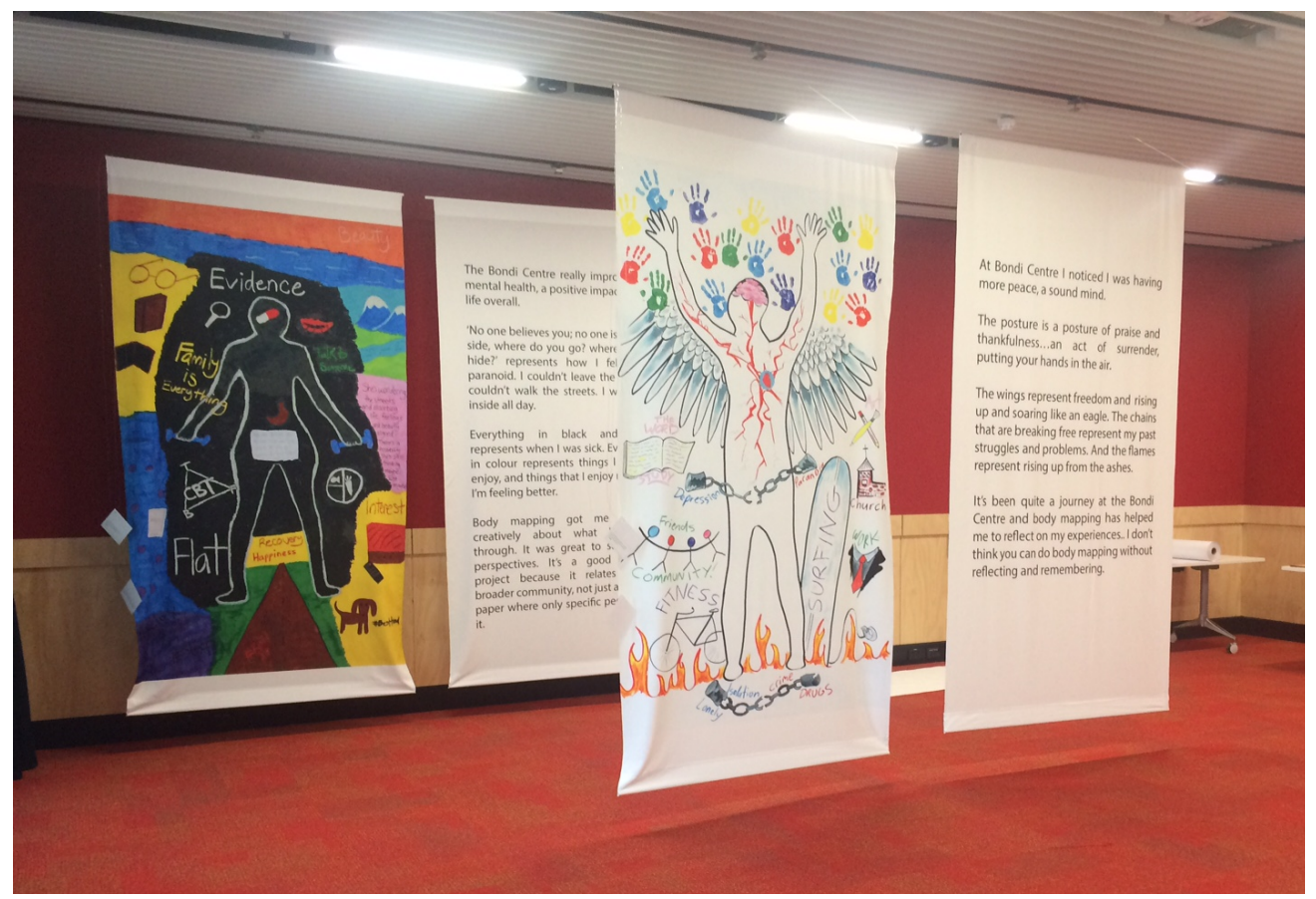

Fig. 1: Body mapping with young people experiencing psychosis 
You've talked about the use of the arts in the production of knowledge, and the beneficial consequences for research participants, but what about communicating research-informed knowledge to others?

Our goal is most certainly to represent research findings via an aesthetic and visceral experience in order to engage audiences in ways that transcend conventional peer-reviewed publications and scientific presentations. When disseminating arts-based research, we are keen to explore the impact on the audience (Larsen, Vaughan, Bennett, \& Boydell, 2018) and contribute to the use of the arts as a knowledge translation strategy. The body mapping project that I described earlier culminated in a dissemination event to share the research findings with a broad audience of service providers, academics, artists, and the general public. We wanted to offer a forum wherein audiences could draw upon their emotions and aesthetics to interpret the research. Our research team partnered with curators from the National Institute of Dramatic Art (NIDA) here in Sydney and we put out an expression of interest to NIDA staff, students, and alumni, asking them to respond to the body maps using their own art genre.

The final dissemination product involved curation of the body maps which were reproduced on 4-by-8-foot silkscreens along with the 25 NIDA responses-including short films, soundscapes, poems, photographic images, sculpture, and a textile composition. "Hold your heart high" was a textile installation by artist Sophie Dieu, reflecting the stories and body maps of young people experiencing psychosis. In their body maps and testimonios, the heart occupies an important place, both symbolically and organically (Figure 2). It represents success during the recovery process and, as such, carries positivity and hope. By extracting the heart from inside the chest and making it fully visible, this work amplifies and acknowledges the role that our body, emotions, and psyche play in our lives. Sublimation - citizen binary, a digital photograph submitted by artist Barbara Doran in response to the body maps, depicts the experience of stigma, of being "marked" by others as different (Figure 3). As Barbara noted in her artist statement,

throughout time and place, no matter who we are or where we, we mark and shape our bodies because they are the sites for creating and knowing ourselves. The possibilities are infinite, but we hear them and sense them by feeling for tiny binary distinctions and arranging them into patterns. We are binary shape shifters. We constantly morph patterns of good and bad, happy and sad, yes and no, on and off, dark and light, loud and quiet, connection and disconnectionthe list goes on.

One can see the ways in which she has taken up the main themes of our body mapping project, the binary distinctions that were identified in participant narratives.

The event launched with a brief overview of the study and its findings to approximately 150 attendees who were then encouraged to engage with the various art installations. We used a mixed-methods approach to "measure" the impact of this dissemination event. An online survey was distributed to attendees prior to, following, and six months after the event to measure knowledge of psychosis, the link between psychosis and poor health, and attitudes towards mental illness. A wall of sticky notes was also collected to obtain immediate responses to the installation and a random sample of attendees were 
interviewed after the event about their experience. Results showed enhanced mental health literacy, and reduced stigma.

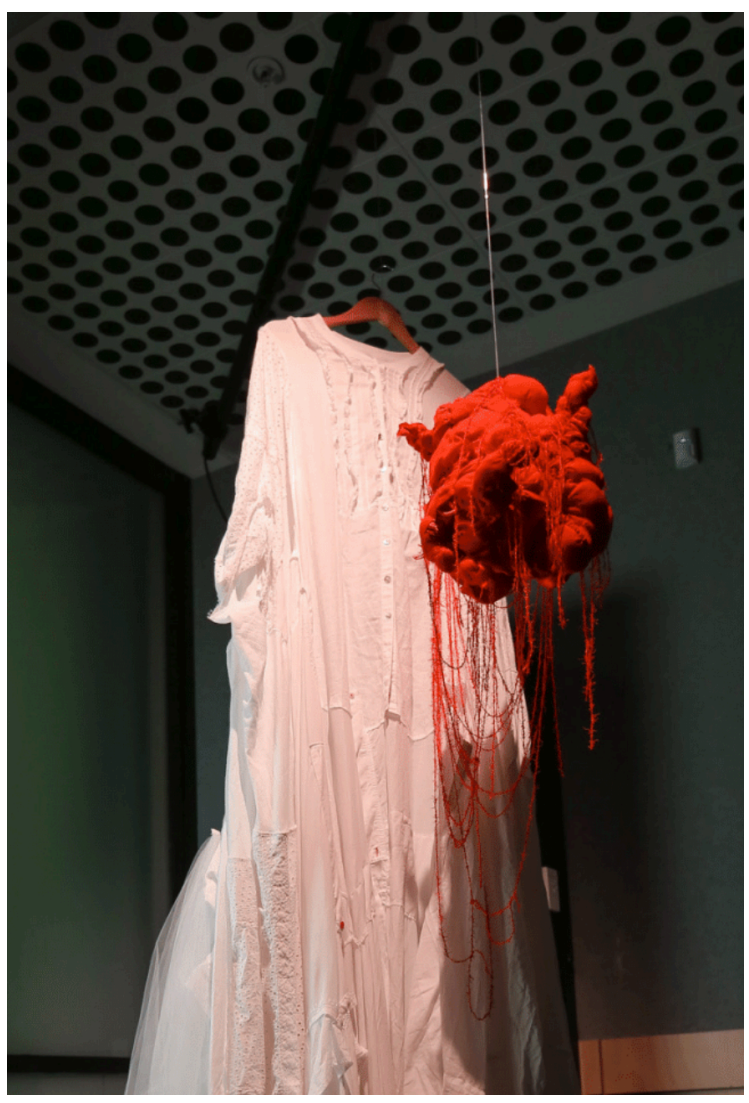

Fig. 2: "Hold your heart high"

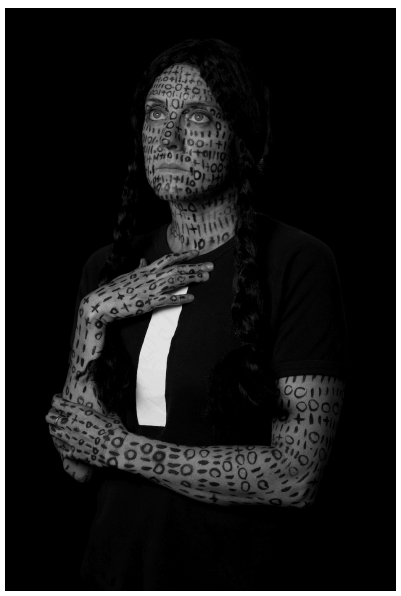

Fig. 3: Sublimation 
For example, respondents indicated that the artwork rendered the subjective experience of psychosis much more accessible to them. The body maps were reported to provide a clear visual link between the mind and the body. The respondents noted that the artworks were interesting, thought provoking, and a powerful way to gain perspective of the experiences of those individuals; it also raised awareness and lowered stigma regarding psychosis. These findings are supported by some of our earlier arts-based dissemination events that indicated they resulted in a greater knowledge base about mental health issues and help seeking (Baker, Willinsky, \& Boydell, 2015; Boydell et al., 2018a).

It appears that you have really been engaged in a great deal of research focused on the use of the arts as a knowledge translation strategy. What do you think are the current gaps in our knowledge about the use of the arts in the research process?

Our scoping review on the use of art genres in health care research identified a number of research gaps (Boydell, Gladstone, Volpe, Allemang, \& Stasiulis, 2012b). Although the 71 articles reviewed described the form and content of the research studies, there was little emphasis on the unique methodological, theoretical, and ethical challenges of engaging in arts-based research. So, we then set out to address these gaps, in particular the many ethical issues inherent in this work. A CIHR-funded planning grant allowed us to bring together an international group of scholars; we identified five central ethical challenges in arts-based health research: (i) authorship and ownership of the work, (ii) truth, interpretation, and representation, (iii) informed consent/anonymity/confidentiality, (iv) dangerous emotional terrain, and $(v)$ issues of aesthetics. These challenges were described in a special journal issue on the topic that our team edited (Boydell et al., 2012a; Gladstone, Volpe, Stasiulis, \& Boydell, 2012). Since that time, we have explored further ethical issues in terms of "dangerous emotional terrain" (Boydell, Solimine, \& Jackson, 2015, 2017b), community-based arts research (Yassi, Lockhart, Fels, \& Boydell, 2016), issues of representation and interpretation (Boydell et al., 2017b), and the implications for ethics committees (Lenette et al., 2018). We have also interrogated the current expectations of what counts in academia and the need to recognize the importance of different ways of knowing-empirical, pragmatic, experiential, and cultural (Boydell, Hodgins, Gladstone, \& Stasiulis, 2017a).

Can you expand a bit on this worry about academic currency and what counts in the university setting?

Our team has written about the tensions experienced regarding academic legitimacy and the use of the arts in producing and disseminating research (Boydell et al., 2017a). Arts-based health research scholars typically work within a culture that values a particular way of knowing, where the academic peer-reviewed article is privileged and where there are "expectations of a linear, evidence-based tradition of writing and presenting research results" (Hodgins \& Boydell, 2014). We argue for the need to reconsider what counts as knowledge and advocate attending to experiential knowledge, pragmatic knowledge, and cultural knowledge in addition to evidence-based research knowledge. As outlined by Greenhalgh and Wierenga (2011), knowledge should be viewed as being "created, constructed, embodied, performed and collectively negotiated" (p. 501). The reconceptualization of notions of evaluation and rigor are also required in order to effectively support the effective production and dissemination of arts-based health research. 
So, where to next? What are your plans for the future?

I am committed to further advance the "science" of arts-based knowledge translation, focusing on a critical interrogation of the theoretical, methodological, practical, and ethical implications of engaging in this work. I am keen to continue to pursue collaborative partnerships with artists, designers, and other creatives in order to embrace performative, visual, and literary ways to produce and communicate empirical research knowledge. What is now required are large longitudinal studies of such arts-based health research projects that focus on what works, for whom and under what conditions. Future projects involve taking arts-based knowledge translation strategies to a new level, researching the potential of using online and virtual reality spaces for participants to create and audiences to engage in/respond to. I am confident that arts-based knowledge translation will facilitate the production of new research knowledge and provide an opportunity to engage both research participant and stakeholder audiences in meaningful ways.

\section{References}

Baker, N., Willinsky, C., \& Boydell, K.M. (2015). Just say know: Creatively engaging young people to explore the link between cannabis use and psychosis in order to promote informed decision-making about substance use. (Invited paper). World Cultural Psychiatry Research Review, 201-220.

Boydell, K.M. (2011a). Using performative art to communicate research: Dancing experiences of psychosis. Canadian Theatre Review, 146, 12-17.

Boydell, K.M. (2011b). Making sense of collective events: The co-creation of a research-based dance. Forum Qualitative Sozialforchung/Forum: Qualitative Social Research, 12(1), Art. 5. Retrieved from http://nbn-resolving.de/urn:nbn:de:0114-fqs110155.

Boydell, K.M., \& Belliveau, G. (2017). Situated methodologies: A critical inquiry into art-based research methodologies. Journal of Applied Arts \& Health, 8(2),135-139.

Boydell, K.M., de Jager, A., Ball, J., Curtis, J., Lappin, J., Kalucy, M., et al. (2018a). Mapping a novel landscape for understanding physical and mental health: Arts-based research with youth experiencing psychosis. Art/Research International, 3(2), 236-261.

Boydell, K.M., Gladstone, B.M., Stasiulis, E., Nodin, S., \& Cheng, C. (2018b). Co-producing narratives on access to care in rural communities: Using digital storytelling to foster social inclusion of young people experiencing psychosis. Studies in Social Justice, 11(2), 298-304.

Boydell, K.M., Gladstone, B.M., Stasiulis, E., Volpe, E., Dhayanhandhan, B., \& Cole, A. (2015b). An aesthetic of knowledge translation: The co-creation of a mural depicting experiences of psychosis (pp. 39-50). In D. Conrad and A. Sinner (Eds.), Creating together. Waterloo, Ontario, Canada: Wilfrid Laurier University Press.

Boydell, K.M., Gladstone, B.M., Volpe, T., Allemang, B., \& Stasiulis, E. (2012b). The production and dissemination of knowledge: A scoping review of arts-based health research. Forum Qualitative Sozialforchung/Forum: Qualitative Social Research, 13(1), Art. 32. 
Boydell, K.M., Hodgins, M.J., Gladstone, B.M., \& Stasiulis, E. (2017a). Ineffable knowledge: Tensions (and solutions) in art-based research representation and dissemination. Journal of Applied Arts \& Health, 8(3), 193-207.

Boydell, K.M., Solimine, C., \& Jackson, S. (2015). Visual embodiment of psychosis:

Ethical concerns when performing difficult experiences. Visual Methodologies, 3(2), 43-52.

Boydell, K.M., Solimine, C., \& Jackson, S. (2017b). Performative dance and the ethics of embodying difficult experiences. In, Ethics for visual research: Theory, methodology and practice.

Boydell, K.M., Volpe, T., Cox, S., Katz, A., Dow, R., Brunger, F., et al. (2012a). Ethical challenges in arts-based health research. International Journal of the Creative Arts in Interprofessional Practice. Spring Suppl Issue. 11.

Cole, A., \& Knowles, G. (2008). Arts-informed research. In A. Cole and G. Knowles (Eds.), Handbook of the arts in qualitative research. Los Angeles, CA: Sage.

Cox, S.M., \& Boydell, K.M. (2016). Ethical issues in arts-based health research. Chapter 11 (pp. 83-91). In P. Camic and L. Wilson (Eds.), Creative arts in public health: International perspectives. London, UK: Oxford University Press.

de Jager, A., Tewson, A., Ludlow, B., \& Boydell, K.M. (2016). Embodied ways of storying the self: A systematic review of body mapping. Forum Qualitative Sozialforchung/Forum: Qualitative Social Research. Retrieved from http://nbn-resolving.de/urn:nbn:de:0114-fqs1602225

de Jager, A., Tewson, A., Vaughan, P., Fogarty, A., \& Boydell, K.M. (2017). Digital storytelling in research: A systematic review. The Qualitative Report, 22(10). Retrieved from http://nsuworks.nova.edu/tqr/vol22/iss10/3/

Gladstone, B.M., Volpe, T., Stasiulis, E., \& Boydell, K.M. (2012). Judging quality in arts-based health research: The case of the ugly baby. International Journal of the Creative Arts in Interprofessional Practice. Spring Supplementary Issue. Issue 11.

Gray, J., \& Kontos, P. (2015). Immersion, embodiment, and imagination: Moving beyond an aesthetic of objectivity in research-informed performance in health. Qualitative Social Research, 162(2), Art. 29.

Greenhalgh, T., \& Wierenga, S. (2011). Is it time to drop the 'knowledge translation' metaphor? A critical literature review. Journal of the Royal Society of Medicine, 104, 501-509.

Hodgins, M., \& Boydell, K.M. (2014). Interrogating ourselves: Reflections on arts-based health research. Forum Qualitative Sozialforchung/Forum: Qualitative Social Research, 15(1), Art. 10.

Larsen, M., Vaughan, P., Bennett, J., \& Boydell, K.M. (2018). The BIG Anxiety project: Visually exploring public experiences and attitudes to anxiety. Journal of Applied Arts \& Health, 9(1). doi:10.1386/jaah.9.1.85_1

Lenette, C., Botfield, J., Boydell, K.M., Haire, B., Newman, C.E., \& Zwi, A. (2018). Beyond compliance checking: A situated approach to visual research ethics. Journal of Bioethical Inquiry.

doi.org/10.1007/s11673-018-9850-0

Parsons, J., \& Boydell, K.M. (2012). Arts-based research and knowledge translation: Some key concerns for health care professionals. Journal of Interprofessional Care, 26(3),170-172. Invited Guest Editorial. 
Romano, D., McCay, E., \& Boydell, K.M. (2012). The use of photographed objects in understanding the process of recovery from a first episode of schizophrenia. Arts and Health, 4(1), 70-82.

Solomon, J. (2002). 'Living with X': A body mapping journey in time of HIV and AIDS. Facilitator's guide. Retrieved from http://www.comminut.com/healthafrica/content/living-x-body-mapping-journeytime-HIV-and-AIDS-facilitator-\%E2\%80\%99s-guide

Tilleczek, K., \& Loebach, J. (2015). Research goes to the cinema: The veracity of videography with, for and by youth. Research in Comparative and International Education, 10(3), 354-366.

Yassi, A., Lockhart, K., Fels, L., \& Boydell, K.M. (2016). Ethics in community-university-artist partnered research: Tensions, contradictions and gaps identified mid-way in a 5-year multi-institutional 'arts for social change' project. Journal of Academic Ethics. doi:10.1007/s10805-016-9257-7

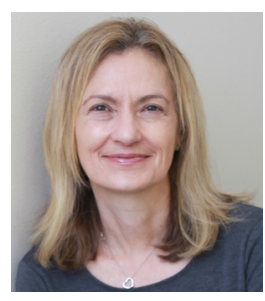

Katherine Boydell is a Professor of Mental Health at The Black Dog Institute, University of New South Wales. Her substantive research focuses on understanding the complex pathways to care for young people experiencing mental ill health, the use of new technologies in child and youth mental health, and the "science" of knowledge translation, while her methodological research examines the advancement of qualitative inquiry, specifically, in the study of arts-based health. She has used documentary film, research-based dance, digital storytelling, body mapping, photovoice, and found poetry in her program of research. She has published more than 200 journal articles and published the only text on qualitative inquiry in the field of early psychosis titled, Hearing Voices: Qualitative Inquiry in Early Psychosis. 